\title{
Physical Strength as a Cue to Men's Capability as Protective Parents
}

\author{
Mitch Brown ${ }^{1,3} \cdot$ Steele Donahoe ${ }^{1} \cdot$ Kaitlyn Boykin ${ }^{2}$ \\ Received: 17 November 2021 / Revised: 19 January 2022 / Accepted: 20 January 2022 \\ (c) The Author(s), under exclusive licence to Springer Nature Switzerland AG 2022
}

\begin{abstract}
The selection of formidable male allies within coalitional settings is partially in the service of ensuring protection from physical threats for group members. Within these inferences could include specific judgments of formidable men as being effective at providing protection for their offspring, a judgment that could facilitate identification of prospective fathers who satisfy parenting goals. The current study sought to identify the specific value of men's physical strength in shaping perceptions of their effectiveness in domains or protection and nurturance of offspring. Participants evaluated physically strong and weak in their effectiveness in these domains. Strong men were perceived as more effective in protecting their offspring than weak men, with this advantage corresponding with strong men being perceived as less effective in nurturance. We frame results from an affordance management framework considering the role of functional inferences shaping interpersonal preferences.
\end{abstract}

Keywords Parenting motives $\cdot$ Formidability $\cdot$ Trade-offs $\cdot$ Protection

Biparental investment has been historically crucial in increasing the inclusive fitness of offspring to ensure their survival into adulthood. This selection pressure would have fostered psychological adaptations to identify prospective mates capable of providing parental opportunities. Women would have especially benefited from prioritizing mates who appeared capable of investing time and resources into offspring to offset the relatively large costs they incur through pregnancy (Buss, 1989; Thomas et al., 2020). One critical aspect of investment potentially includes men's ability to ensure safety for offspring through physical protection (Kokko et al., 2003). Within this suite of adaptive inferences is acuity toward physical features connoting physical prowess that implicate strong men as protective fathers (Sell et al., 2008). From an affordance management perspective (Neuberg et al., 2020), acuity toward men's strength would lead to an understanding of how these features indicate men's capabilities to facilitate or impede social goals of the perceiver, resulting in

Mitch Brown

mb103@uark.edu

1 University of Arkansas, Fayetteville, AR, USA

2 The University of Southern Mississippi, Hattiesburg, MS, USA

3 Department of Psychological Science, University of Arkansas, Fayetteville, AR 72701, USA motivations to approach or avoid social targets based on their salient affordances (Zebrowitz \& Montepare, 2006).

Inferences of parental ability are multimodal. Individuals rely on various physical cues when making these judgments (Brown et al., 2021a). For inferences of men's abilities, body fat and facial hair are perceived as diagnostic of their capability to provide extensive care for their offspring (Dixson \& Brooks, 2013; Sacco et al., 2020). The signal values of these features appear specific to parental warmth and resource provisioning. Body fat is relatively diagnostic of reduced testosterone levels that would decrease the likelihood of aggression toward a child (Gray \& Campbell, 2009), whereas facial hair could connote greater earning power through inferred higher status. Despite these affordances of warmth through features, such cues may not connote men's ability to protect their offspring. High levels of body fat present physical disadvantages that could impede success in conflict (e.g., Lassek \& Gaulin, 2009), and facial hair is not a veridically diagnostic fighting ability (Dixson et al., 2018). These protective capabilities could be more reliably inferred through men's upper body strength due to both formidable men's advantages in physical conflict (Puts, 2010) and the above-chance accuracy humans demonstrate toward cues to strength (Lukaszewski et al., 2016). This study sought to identify the specific signal value of physical strength in parenting domains by particularly considering its role in connoting men's capability of protecting offspring. 


\section{Parenting Motivational Systems}

Humans' reproductive success relies on extensive parental care to ensure their offspring survive into adulthood. The selection pressures to provide parental care led to the evolution of extensive parental care motivational systems (Schaller, 2020). Recent research provides evidence for these psychological mechanisms. Humans are sensitive to young children and neotenous features (Kringelbach et al., 2016; Woo \& Schaller, 2020). These cues elicit feelings of tenderness as a proxy for motivation to care for children (Sherman et al., 2009). Activation of parenting motives further heightens monogamous intent (Beall \& Schaller, 2019) and vigilance toward threats (Gilead \& Liberman, 2014). Individuals vary naturally in activation of this motivational system. Those exhibiting chronic activation of this motivational system demonstrate greater visual interest in infants (Buckels et al., 2015). This parental care system appears comprised of separate systems relevant to domains of protecting and nurturing offspring (Hofer et al., 2018). Recent findings provide evidence of the nurturance system. The visual appearance of babies is rewarding, eliciting feelings of warmth (Glocker et al., 2009). Evidence for this protective system similarly exists. Breastfeeding mothers are particularly aggressive toward hostile strangers (Hahn-Holbrook et al., 2011). Interactions with children further foster vigilant social attitudes that could facilitate protection (Kerry \& Murray, 2020).

Given individuals' capability of identifying the salience of fundamental social motives through physical features (e.g., Antar \& Stephen, 2021; Brown et al., in press-a), it remains unsurprising that similar inferences are possible through such features in identifying parental motivations. Women possessing highly feminized facial features exhibit considerable maternal motivations and are perceived as such (Smith et al., 2012). Large breasts are additionally inferred as diagnostic of women's capabilities to nurture offspring, an inference rooted in recognition of additional metabolic resources they possess (Dixson et al., 2015; Sacco et al., 2020). The capability to infer activation of this motivational system could suggest it possible to identify those who appear motivated by protection. This inference could be critical in identifying men's parental affordances, given men's heightened motivation for protection at the expense of nurturing (Hofer et al., 2018). This trade-off would prioritize identifying protective fathers, especially considering the fewer costs they face in physical conflict (Griskevicius et al., 2009).

\section{Parental Affordances of Formidability}

Physical conflict has been prevalent throughout human evolutionary history. The coevolution of conflict with men's advantage in formidability has led to conflict becoming sexually asymmetric, with men's participation being more frequent (Sell et al., 2012). Men's greater muscle mass compared to women's positions them for considerable advantages in combat. One basis for men's social selection is their formidability, as frequently indexed through upper body strength (Lukaszewski et al., 2016; von Rueden et al., 2014). Formidable men's advantage in intrasexual competition could subsequently connote their heritable fitness to prospective mates, leading to upper body strength becoming sexually selected itself (Frederick \& Haselton, 2007; Puts, 2010; Sell et al., 2017). These inferences of coalitional value appear unique to men's formidability, given men's greater proclivity toward physical conflict that necessitates acuity specifically to male features (Sell et al., 2008).

Formidable men's prowess could implicate them as particularly effective in facilitating coalitional goals, manifesting as a cross-cultural desirability of upper body strength for coalitional tasks involving intergroup protection (Apicella, 2014; Lukaszewski et al., 2016; von Rueden et al., 2014). Men and women frequently choose formidable men to be coalitional allies when concerns of physical safety and crime are salient (Brown et al., 2017; Meskelyte \& Lyons, 2020; Sacco et al., 2015). Formidable men are also selected more frequently for tasks that may require protection from intergroup threats (Brown et al., 2021b). These inferred benefits in protective domains could have downstream consequences in parenting domains, with strong fathers being seen as particularly effective at protecting offspring.

Despite formidable men's coalitional advantage, several interpersonal costs could be duly salient that implicate them as suboptimal parents in certain domains. Strong men's favorability toward promiscuity suggests a general disinterest in long-term pair bonds necessary for biparental investment, thus undermining perceptions of their capability to nurture (Frederick \& Haselton, 2007; Gallup et al., 2007). In fact, cues to formidability are frequently inferred as diagnostic of this disinterest in men (Brown et al., in press-a). These concomitant judgments with their coalitional value present a potential trade-off in their inferred parental value. Individuals' inferences of strength's parental value appear limited to protection domains at the expense of their ability to nurture (for discussion on this tradeoff logic, see Brown, 2021). Muscular men are inferred as being less capable of nurturance (Sacco et al., 2020). These costs appear especially salient in harsh ecologies. Women are especially averse to masculine features in these environments, shaped in perceptions of them being typical of aggressors more than protectors (Borras-Guevara et al., 2017; Gallup et al., 2007). Several concomitant perceptions could emerge implicating these men as imposing costs on their own offspring. In particular, strong men could be seen as more likely 
Fig. 1 Example target strong (left) and weak bodies
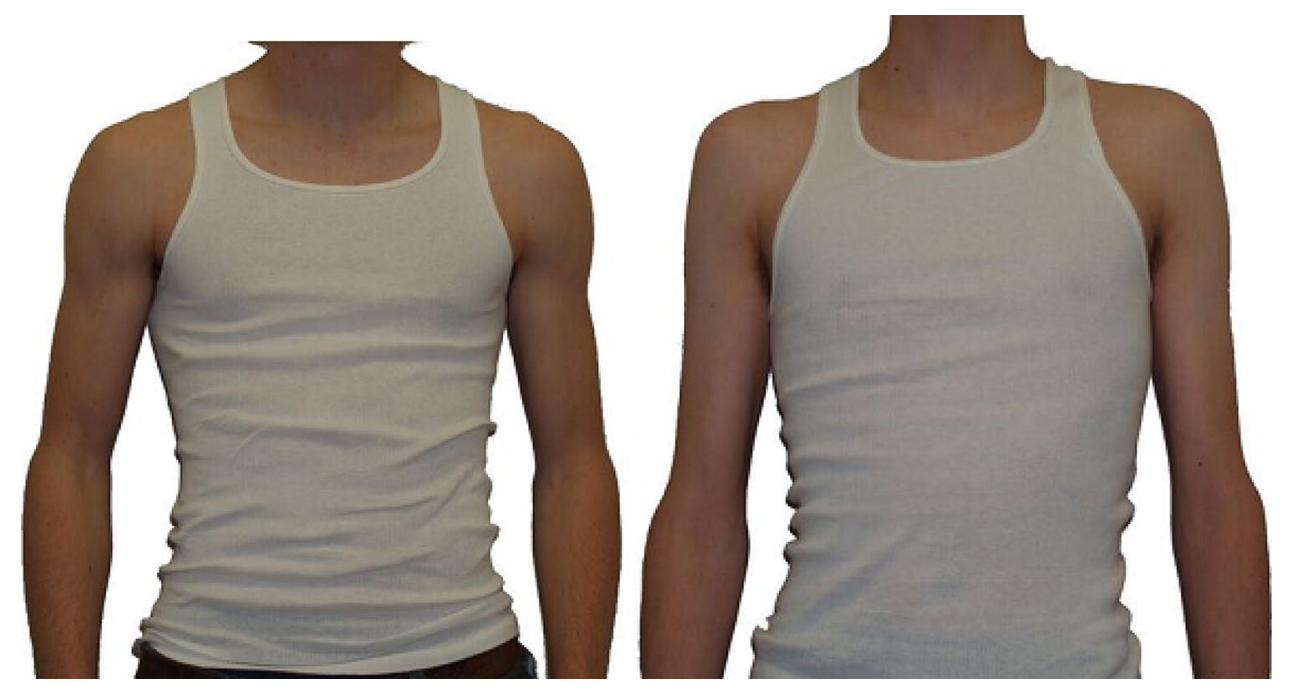

to employ aggressive disciplinary strategies toward their offspring (e.g., corporal punishment). Formidable men indeed report greater endorsement of aggressive punishments (Urbatsch, 2021), which could serve as a metric to infer their preferred method of disciplining children. Taken together, the frequent employment of aggressive behavioral strategies among formidable men could facilitate perceptions of their preferred disciplinary style.

\section{Current Research}

We sought to identify the affordance judgments of men's parental capabilities across parenting domains (Hofer et al., 2018). The physical size asymmetry advantaging men in conflict led us to consider men's upper body strength. We considered how inferences shaped perceptions of men's capability to protect offspring and whether it evoked trade-offs in perceptions of nurturance. Given research suggesting formidable men are desirable for intergroup conflict (Lukaszewski et al., 2016), we predicted strong men would be perceived as more effective in protecting offspring than weak men. Conversely, formidable men's interest in promiscuity led us to predict them to be perceived as less effective in nurturance (Gallup et al., 2007).

We considered the trade-off within parental domains related to disciplining offspring. Given the greater proclivity of stronger men to employ aggressive interpersonal styles that could implicate them as preferring authoritarian attitudes (Brown et al., 2021c; Lukaszewski, 2013; Urbatsch, 2021), we predicted strong men would be perceived as more likely to use physical discipline. Conversely, interest in physical discipline led us to predict such men to be seen as unlikely to employ constructive discipline (Sacco et al., 2020). To understand perceptual bases of these affordance judgments, we considered whether strength or anger would be more diagnostic of perceived parental efficacies. ${ }^{1}$

\section{Method}

\section{Participants}

We recruited 159 undergraduates from a large public university in Southeastern USA for course credit (109 women, $50 \mathrm{men} ; M_{\mathrm{Age}}=18.70, S D=1.23 ; 84.3 \%$ White). A sensitivity analysis indicated we were adequately powered to detect small effects in a $2 \times 2$ within-subject analysis (Cohen's $f=0.11,1-\beta=0.80)$. No data were excluded from final analyses.

\section{Materials and Procedure}

\section{Target Strength}

Participants evaluated eight unique identities. Four identities were of physically strong men and four were of physically weak men. Target strength was ascertained by an electronic dynamometer from which targets provided a composite measure of upper body strength derived from a chest press and hand grip (Lukaszewski et al., 2016). Targets categorized as strong exhibited greater upper body strength, which is accurately inferred by perceivers (see Fig. 1 for example bodies). Targets wore white tank tops for standardization. Because of the "wifebeater" stereotype possibly influencing responses from the tank tops, we addressed this

\footnotetext{
${ }^{1}$ We report all measures, manipulations, and data exclusions. data, syntax, and materials utilized in this study are publicly available through: https:// osf.io/ha64q/?view_only=446d096cb61845259dcb40fde99d10c3
} 
standardization in the instructions to minimize biases. Targets appeared in random order.

Participants indicated how strong each target body appeared with a single-item manipulation check $(1=$ Not at All Strong; 7 = Very Strong). We used two additional affordance judgments for upper body strength assessing perceived aggression and how of a bad temper they ostensibly have ( $1=$ Not Aggressive/Bad at All; $7=$ Very Aggressivel $\mathrm{Bad}$ ). These items were highly correlated across categories ( $r \mathrm{~s}>0.92)$. This prompted us to aggregate these items into a single outcome we deemed perceived anger.

\section{Parental Affordance Judgments}

Participants evaluated targets' parental abilities using two items assessing how effective they appeared to be in satisfying goals related to the two parental motivational systems of nurturance and protection (Hofer et al., 2018). Items operated along 7-point scales $(1=$ Not at All; $7=$ Very $M u c h)$. Targets were additionally assessed on the likelihood they would use physical punishment on children and verbal discipline.

\section{Results}

\section{Manipulation Checks}

Paired samples $t$-tests indicated strong targets were perceived as stronger and angrier than weak targets (Table 1). One samples $t$-tests weighted against a midpoint of four indicated strong and weak targets were respectively perceived as categorically strong and weak, $|t \mathrm{~s}|>6.29$, ps $<0.001$, and $d \mathrm{~s}>0.49$. Weak targets were perceived as non-angry, $t(158)=-9.23, p<0.001$, and $d=0.73$. Strong targets were perceived as neither angry nor non-angry, $t(158)=0.60$, $p=0.550$, and $d=0.05$.

\section{Parental Effectiveness}

We conducted a 2 (Target Strength: Strong vs. Weak) $\times 2$ (Parenting Motive: Protection vs. Nurturance) repeated-measures ANOVA. A Target Strength main effect indicated strong targets were perceived as more effective parents $(M=4.04$,

Table 1 Perceived affordances of strong and weak targets (with standard deviations)

\begin{tabular}{lllrl}
\hline & Strong & Weak & \multicolumn{1}{l}{$t$} & $d$ \\
\hline Strength & $4.40(0.80)$ & $3.03(0.75)$ & $23.60^{*}$ & 1.87 \\
Anger & $4.03(0.76)$ & $3.41(0.80)$ & $9.71^{*}$ & 0.77 \\
\hline
\end{tabular}

${ }^{*} p<0.001$

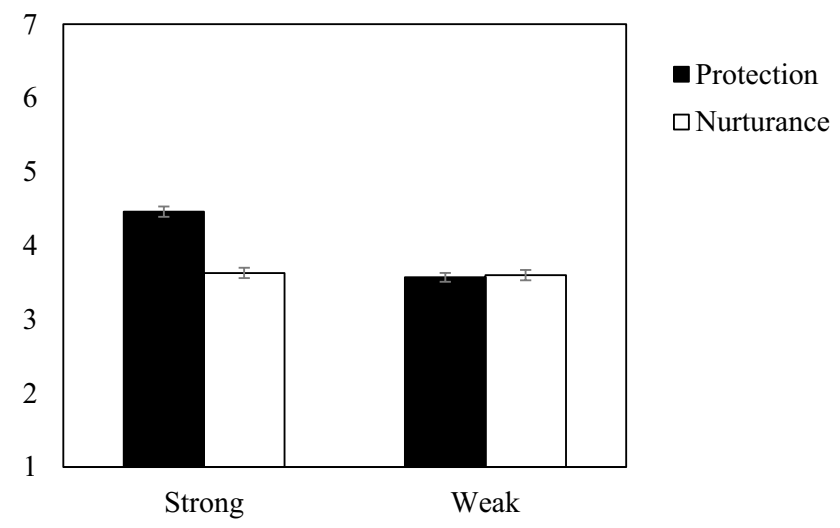

Fig. 2 Perceived effectiveness of strong and weak targets in protection and nurturance domains (with standard error bars)

$S D=0.83)$ than weak targets $(M=3.58, S D=0.88), F(1$, 158) $=73.55, p<0.001$, and $\eta_{\mathrm{p}}{ }^{2}=0.318$. A Parenting Motive main effect additionally indicated targets were perceived as more effective in protection $(M=4.01, S D=0.88)$ than nurturance $(M=3.61, S D=0.83), F(1,158)=80.85, p<0.001$, and $\eta_{\mathrm{p}}{ }^{2}=0.339$.

A Target Strength $\times$ Parenting Motive interaction emerged, $F(1,158)=124.12, p<0.001$, and $\eta_{\mathrm{p}}{ }^{2}=0.440$ (Fig. 2). Simple effects indicated strong targets were perceived as more effective at protection $(M=4.46, S D=0.87)$ than weak targets $(M=3.57, S D=0.89), F(1,158)=169.42, p<0.001$, and $\eta_{\mathrm{p}}{ }^{2}=0.517$. No difference emerged in perceiving nurturing ability among strong $(M=3.63, S D=0.79)$ and weak targets $(M=3.60, S D=0.87), F(1,158)=0.27, p=0.601$, and $\eta_{\mathrm{p}}{ }^{2}=0.002$. Strong targets were perceived as more effective at protection than nurturance, $F(1,158)=180.92, p<0.001$, and $\eta_{\mathrm{p}}{ }^{2}=0.534$. No difference emerged for weak targets, $F(1$, 158) $=0.23, p=0.628$, and $\eta_{\mathrm{p}}{ }^{2}=0.001$. One samples $t$-tests indicated both categories of targets elicited perceptions of categorical ineffectiveness in nurturance, $|t s|>5.75, p s<0.001$, and $d \mathrm{~s}>0.45$. Strong targets were perceived as categorically protective, $t(158)=6.73, p<0.001$, and $d=0.53$.

\section{Disciplinary Strategies}

We employed a 2 (Target Strength: Strong vs. Weak) $\times 2$ (Disciplinary Strategy: Physical vs. Verbal) repeated-measures ANOVA. A Disciplinary Strategy main effect additionally indicated targets were perceived as more likely to use verbal tactics $(M=3.63, S D=0.89)$ than physical punishment $(M=3.46$, $S D=0.82), F(1,158)=4.50, p=0.035$, and $\eta_{\mathrm{p}}{ }^{2}=0.028$. The Target Strength main effect target was not significant, $F(1$, 158) $=2.57, p=0.111$, and $\eta_{\mathrm{p}}{ }^{2}=0.016$.

A Target Strength $\times$ Disciplinary Strategy interaction emerged, $F(1,158)=27.96, p<0.001$, and $\eta_{\mathrm{p}}{ }^{2}=0.150$ (Fig. 3). Simple effects indicated strong targets were perceived as more 


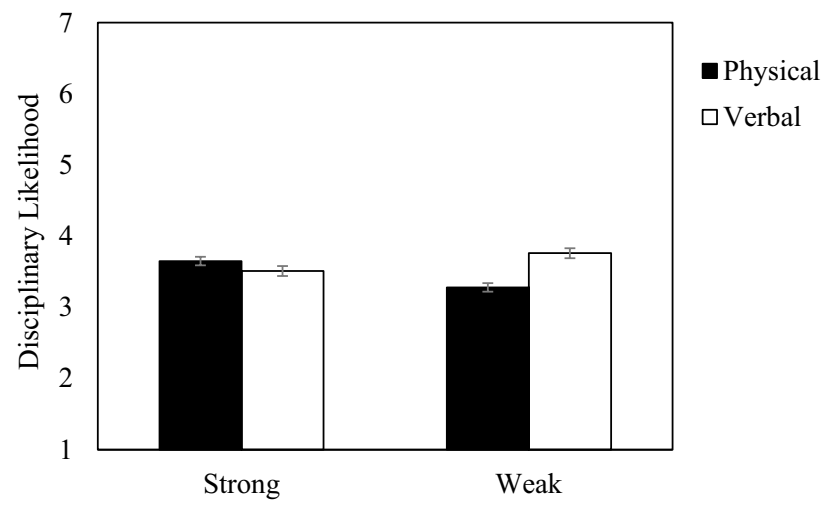

Fig. 3 Perceived likelihood of strong and weak targets to employ physical and verbal disciplinary tactics (with standard error bars)

likely to punish children physically $(M=3.65, S D=0.80)$ than weak targets $(M=3.28, S D=0.85), F(1,158)=29.30, p<0.001$, and $\eta_{\mathrm{p}}{ }^{2}=0.156$. Weak targets were perceived as more likely to use verbal tactics $(M=3.76, S D=0.93)$ than strong targets $(M=3.51, S D=0.85), F(1,158)=12.39, p=0.001$, and $\eta_{\mathrm{p}}{ }^{2}=0.073$. Weak targets were perceived as more likely to use verbal tactics than physical, $F(1,158)=19.73, p<0.001$, and $\eta_{\mathrm{p}}{ }^{2}=0.111$. No difference emerged for strong targets, $F(1$, 158) $=2.01, p=0.158$, and $\eta_{\mathrm{p}}{ }^{2}=0.013$. One sampled $t$-tests indicated all targets were perceived as categorically unlikely to employ disciplinary strategies, $|t s|>3.17, p s<0.003$, and $d \mathrm{~s}>0.25 .^{2}$

\section{Bases of Parental Affordances}

Our next step was to identify the perceptual bases of these social judgments. We correlated perceptions of strength and anger with relevant affordances. The fully within-subjects nature of these analyses led us to calculate difference scores for the strong and weak targets in these domains; higher scores represented higher levels from strong targets.

We considered correlations of perceived strength and anger with effectiveness in protection exclusively. This was because the perceived effectiveness in protection was significantly above and below the midpoints for strong and weak targets, respectively. Target categories were all perceived as categorically ineffective at nurturing and unlikely to employ discipline, thus leading us not to consider these analyses further. The perceived strength advantage of strong targets was positively correlated with perceived effectiveness of strong men in protecting their offspring $(r=0.51$, $p<0.001)$. No association emerged for anger and perceived effectiveness in protection $(r=0.04, p=0.616)$.

\footnotetext{
${ }^{2}$ When including Participant Sex in the models as a moderator, the reported 2-way interactions remained significant. Including this variable did not elicit 3-way interactions.
}

\section{Discussion}

Results supported several hypotheses related to the inferred benefits of formidability in fathers. Physically strong men were perceived as particularly effective at protecting their offspring, an inference that aligns with previous research suggesting a salient benefit of formidability among those motivated by concerns for their physical safety (Snyder et al., 2011). This perceived benefit suggests a degree of generalizability between fundamental motives involved with protection to where one's coalitional value appears to overlap with parental value, indicating the importance of men's formidability in parental care (Kokko et al., 2003). This point is bolstered by the basis of this protection advantage in strong targets being rooted in perceptions of men's actual strength, suggesting that actual physical abilities inform judgments beyond displays of aggression that may not reflect actual formidability. For example, facial hair augments perceptions formidability (Craig et al., 2019; Dixson et al., 2021), yet beards appear unrelated to actual formidability (Dixson et al., 2018). Our findings indicate putative cues to formidability inform potentially accurate perceptions of men's ability to protect their families.

The perceived advantage in protection for strong targets was regarded as a trade-off with their ability to nurture offspring being downregulated. This inference could reflect conflicting perceptions of formidable men as disinterested in monogamous behaviors (Gallup et al., 2007), highlighting the potential costs of effective protectors in parenting domains despite the salient benefits. Men motivated by protective motives are further interested in promiscuous mating strategies (Beall \& Schaller, 2019), suggesting this perceived ineffectiveness in nurturance could reflect disinterest in other components of biparental investment beyond protection.

In addition to this, inferred cost of formidability is a concomitant perception of strong men as being more prone to employ physical punishment on their children instead of using verbal disciplinary tactics. This difference could represent an additional trade-off. Although authoritarian parenting typified by physical discipline could foster greater compliance from offspring in a hostile environment (Roccato et al., 2014), such discipline poses several risks. The size asymmetry that advantages strong men in physical conflict could guarantee more serious injuries toward their offspring if they employ excessive physical discipline. However, this perceived trade-off did not necessarily position physically weak men to be perceived as affording additional benefits despite previous findings demonstrating an advantage of less formidable men in parental domains (Sacco et al., 2020). This discrepancy between findings may suggest that the perceived lack of effectiveness the weak targets connoted could 
represent an absence of a salient cue that was apparent in previous work (i.e., adiposity).

As referenced in the footnote, men and women did not differ in their perceptions of parenting affordances. Although inferences of men's formidability would provide an adaptive advantage for both men and women in navigating conflict, such inferences may nonetheless serve different functions. Women's inferences could facilitate their identification of prospective mates most capable of optimizing parental care. Men's inferences may conversely be shaped by an understanding of these bodily cues' connotation of intrasexual competition as if they were behaviors diagnostic monogamous intent (Brown et al., in press-b), given the connection between the protection motives and interest in promiscuity (Beall \& Schaller, 2019). Our data could reflect vigilance toward the interpersonal costs of formidable fathers as threats to other men's mating goals. Alternatively, despite a subsequent sensitivity analysis indicating adequate power to detect small effects with a single betweensubjects factor $(f=0.11,1-\beta=0.80)$, the relatively small sample of men could have led to this study being underpowered. Being underpowered would have precluded us from testing moderation for a between-subject factor (Blake \& Gangestad, 2020). A larger sample would afford us the opportunity to identify potential sex differences while identifying the specific bases of affordance judgments.

\section{Limitations and Future Directions}

Although the current study provided evidence that was largely consistent with predictions, several limitations emerged that would warrant future studies. One limitation is the fact these results are rooted in stereotypes of formidability. Future research would benefit from specifically assessing men's formidability in addition to their chronic activation of parental care motives to determine whether formidability corresponds with actual parenting motives (Shoup \& Gallup, 2008). A subsequent study could then task perceivers with evaluating the degree they perceive formidability as a veridical cue to these parenting motives. Given endorsement of promiscuous mating strategies corresponds with both formidability and a motivation to protect offspring (Beall \& Schaller, 2019; Gallup et al., 2007), it would seem sensible to predict formidable men are more protective offspring and that this information is accurately inferred.

Another limitation emerges based on the potential reproductive interest in this sample. We recruited a sample of undergraduates in this study whose likely relative lack of parental experience could have provided a more developmentally constrained understanding of these inferences. Though parental motives are certainly capable of being activated among undergraduates and non-parents (e.g., Kerry \& Murray, 2018), it could be possible that these effects are amplified among those with children. Acuity toward the signal value of secondary sex characteristics increases during pregnancy in women (Dixson et al., 2019; Marcinkowska et al., 2018), suggesting highly salient reminders of childcare could potentially heighten awareness of formidability's parental value.

Despite the benefit of protection through physical strength, it remains less clear which features in men are more diagnostic of satisfying nurturance domains. Given the potential corollary of strength with dominance, it could be advantageous to consider features diagnostic of interpersonal warmth. Such cues may include body fat (Sacco et al., 2020) or agreeable facial structures (Brown et al., 2019), given previous findings indicating these features' connotation of satisfying relationship and parenting goals. Future research would further benefit from considering cues to warmth and dominance within the same study and determine how perceivers identify the potential trade-off between these parenting motives. Additionally, another component of women's criteria for prospective fathers concerns their ability to provide resources (e.g., Lee et al., 2013). Future research would benefit from determining the extent these various affordance cues may be diagnostic of their potential for resource provision.

These potential costs and benefits of formidability appear perceptually salient. Nonetheless, it remains less clear whether specific motivational states could facilitate greater salience of costs and benefits for formidability in parenting domains. Future studies could assess individual differences in self-protection motives and determine the extent individuals perceive strength as imperative for fathers based on chronic safety concerns (Brown et al., 2017; Snyder et al., 2011). Conversely, it could be possible that particularly harsh ecologies facilitate perceptions of formidable fathers as prone to physically aggressing against their family, thus undermining strong men's desirability as parents (Allen et al., 2016). A future study could compare perceptions of formidability in parenting domains across ecologies with differing degrees of harshness. This research would further benefit from considering cross-cultural differences in these perceptions, given a general aversion to masculinized features in harsher ecologies (Borras-Guevara et al., 2017; Brooks et al., 2011; Marcinkowska et al., 2019). This fact could reflect the costs of formidable men as more salient than the benefits in these environments.

\section{Conclusion}

Identification of men capable of investing in offspring is often critical for reproductive success, thereby necessitating consideration of various features diagnostic of that ability. Physical formidability appears to be a particularly relevant trait for these inferences. In this study, we found that strong 
men are perceived as particularly effective at protecting their offspring. Such an inference appears functional to increase this reproductive success.

Author Contribution MB was involved in conceptualization and implementation of this study, conducted primary analyses, and wrote the initial draft; SD programmed the study and provided edits; KB was involved in conceptualization of this study and provided edits.

Funding Not applicable.

Availability of Data and Material OSF link available in manuscript.

Code Availability Code is available through OSF link.

\section{Declarations}

Ethics Approval This study had IRB approval.

Consent to Participate Participants provided informed consent.

Consent for Publication All authors approved of this submission.

Conflict of Interest The authors declare no competing interests.

\section{References}

Allen, M. W., Bettinger, R. L., Codding, B. F., Jones, T. L., \& Schwitalla, A. W. (2016). Resource scarcity drives lethal aggression among prehistoric hunter-gatherers in central California. Proceedings of the National Academy of Sciences, 113, 12120-12125.

Antar, J. C., \& Stephen, I. D. (2021). Facial shape provides a valid cue to sociosexuality in men but not women. Evolution and Human Behavior, 42, 361-370.

Apicella, C. L. (2014). Upper-body strength predicts hunting reputation and reproductive success in Hadza hunter-gatherers. Evolution and Human Behavior, 35, 508-518.

Beall, A. T., \& Schaller, M. (2019). Evolution, motivation, and the mating/parenting trade-off. Self and Identity, 18(1), 39-59.

Blake, K. R., \& Gangestad, S. (2020). On attenuated interactions, measurement error, and statistical power: Guidelines for social and personality psychologists. Personality and Social Psychology Bulletin, 46, 1702-1711.

Borras-Guevara, M. L., Batres, C., \& Perrett, D. I. (2017). Aggressor or protector? Experiences and perceptions of violence predict preferences for masculinity. Evolution and Human Behavior, 38, 481-489.

Brooks, R., Scott, I. M., Maklakov, A. A., Kasumovic, M. M., Clark, A. P., \& Penton-Voak, I. S. (2011). National income inequality predicts women's preferences for masculinised faces better than health does. Proceedings of the Royal Society b: Biological Sciences, 278, 810-812.

Brown, M. (2021). Goal relevance and desirability of virtuous behavior in satisfying affiliative and pathogen avoidance needs. Personality and Individual Differences, 181, 111025.

Brown, M., Sacco, D. F., Boykin, K., Drea, K. M., \& Macchione, A. L. (2021a). Inferences of parental ability through facial and bodily features. In V. A. Weekes-Shackelford \& T. K. Shackelford (Eds.), The Oxford Handbook of Evolutionary Psychology and Parenting (pp. 453-467). Oxford University Press.
Brown, M., Boykin, K., \& Sacco, D. F. (in press-a). Inferring preferred mating strategies through body fat and sex-typical body features. Journal of Social and Personal Relationships.

Brown, M., Keefer, L. A., Sacco, D. F., \& Brown, F. L. (in press-b). Demonstrate values: Behavioral displays of moral outrage as a cue to long-term mate potential. Emotion.

Brown, M., Sacco, D., Barbaro, N., \& Drea, K. (2021b). Contextual factors that heighten interest in coalitional alliances with men possessing formidable facial structures. Preprint available at PsyArxiv.

Brown, M., Sacco, D., \& Lukaszewski, A. (2021c). Physical strength as a heuristic cue of political conservatism. Preprint available at PsyArxiv.

Brown, M., Sacco, D. F., \& Medlin, M. M. (2019). Sociosexual attitudes differentially predict men and women's preferences for agreeable male faces. Personality and Individual Differences, $141,248-251$.

Brown, M., Sacco, D. F., Lolley, K. P., \& Block, D. (2017). Facing the implications: Dangerous world beliefs differentially predict men and women's aversion to facially communicated psychopathy. Personality and Individual Differences, 116, 1-5.

Buckels, E. E., Beall, A. T., Hofer, M. K., Lin, E. Y., Zhou, Z., \& Schaller, M. (2015). Individual differences in activation of the parental care motivational system: Assessment, prediction, and implications. Journal of Personality and Social Psychology, 108, 497-514.

Buss, D. M. (1989). Sex differences in human mate preferences: Evolutionary hypotheses tested in 37 cultures. Behavioral and Brain Sciences, 12, 1-14.

Craig, B. M., Nelson, N. L., \& Dixson, B. J. (2019). Sexual selection, agonistic signaling, and the effect of beards on recognition of men's anger displays. Psychological Science, 30, 728-738.

Dixson, B. J. W., Barkhuizen, C. L., \& Craig, B. M. (2021). Beardedness increases the speed, accuracy, and explicit judgments of facial threat. Adaptive Human Behavior and Physiology, 7, $347-362$.

Dixson, B. J., \& Brooks, R. C. (2013). The role of facial hair in women's perceptions of men's attractiveness, health, masculinity and parenting abilities. Evolution and Human Behavior, 34, 236-241.

Dixson, B. J., Duncan, M., \& Dixson, A. F. (2015). The role of breast size and areolar pigmentation in perceptions of women's sexual attractiveness, reproductive health, sexual maturity, maternal nurturing abilities, and age. Archives of Sexual Behavior, 44, 1685-1695.

Dixson, B. J., Kennedy-Costantini, S., Lee, A. J., \& Nelson, N. L. (2019). Mothers are sensitive to men's beards as a potential cue of paternal investment. Hormones and Behavior, 113, 55-66.

Dixson, B. J., Sherlock, J. M., Cornwell, W. K., \& Kasumovic, M. M. (2018). Contest competition and men's facial hair: Beards may not provide advantages in combat. Evolution and Human Behavior, 39, 147-153.

Frederick, D. A., \& Haselton, M. G. (2007). Why is muscularity sexy? Tests of the fitness indicator hypothesis. Personality and Social Psychology Bulletin, 33, 1167-1183.

Gallup, A. C., White, D. D., \& Gallup, G. G., Jr. (2007). Handgrip strength predicts sexual behavior, body morphology, and aggression in male college students. Evolution and Human Behavior, $28,423-429$.

Gilead, M., \& Liberman, N. (2014). We take care of our own: Caregiving salience increases out-group bias in response to out-group threat. Psychological Science, 25, 1380-1387.

Glocker, M. L., Langleben, D. D., Ruparel, K., Loughead, J. W., Valdez, J. N., Griffin, M. D., \& Gur, R. C. (2009). Baby schema modulates the brain reward system in nulliparous women. Proceedings of the National Academy of Sciences, 106, 9115-9119.

Gray, P. B., \& Campbell, B. C. (2009). Human male testosterone, pairbonding, and fatherhood. In P. T. Ellison \& P. B. Gray (Eds.), 
Endocrinology of Social Relationships (pp. 270-293). Harvard University Press.

Griskevicius, V., Tybur, J. M., Gangestad, S. W., Perea, E. F., Shapiro, J. R., \& Kenrick, D. T. (2009). Aggress to impress: Hostility as an evolved context-dependent strategy. Journal of Personality and Social Psychology, 96, 980-994.

Hahn-Holbrook, J., Holt-Lunstad, J., Holbrook, C., Coyne, S. M., \& Lawson, E. T. (2011). Maternal defense: Breast feeding increases aggression by reducing stress. Psychological Science, 22, $1288-1295$.

Hofer, M. K., Buckels, E. E., White, C. J., Beall, A. T., \& Schaller, M. (2018). Individual differences in activation of the parental care motivational system: An empirical distinction between protection and nurturance. Social Psychological and Personality Science, 9, 907-916.

Kerry, N., \& Murray, D. R. (2018). Conservative parenting: Investigating the relationships between parenthood, moral judgment, and social conservatism. Personality and Individual Differences, 134, 88-96.

Kerry, N., \& Murray, D. R. (2020). Politics and parental care: Experimental and mediational tests of the causal link between parenting motivation and social conservatism. Social Psychological and Personality Science, 11, 284-292.

Kokko, H., Brooks, R., Jennions, M. D., \& Morley, J. (2003). The evolution of mate choice and mating biases. Proceedings of the Royal Society of London. Series B: Biological Sciences, 270, 653-664.

Kringelbach, M. L., Stark, E. A., Alexander, C., Bornstein, M. H., \& Stein, A. (2016). On cuteness: Unlocking the parental brain and beyond. Trends in Cognitive Sciences, 20, 545-558.

Lassek, W. D., \& Gaulin, S. J. (2009). Costs and benefits of fat-free muscle mass in men: Relationship to mating success, dietary requirements, and native immunity. Evolution and Human Behavior, 30, 322-328.

Lee, A. J., Dubbs, S. L., Kelly, A. J., von Hippel, W., Brooks, R. C., \& Zietsch, B. P. (2013). Human facial attributes, but not perceived intelligence, are used as cues of health and resource provision potential. Behavioral Ecology, 24, 779-787.

Lukaszewski, A. W. (2013). Testing an adaptationist theory of trait covariation: Relative bargaining power as a common calibrator of an interpersonal syndrome. European Journal of Personality, $27,328-345$.

Lukaszewski, A. W., Simmons, Z. L., Anderson, C., \& Roney, J. R. (2016). The role of physical formidability in human social status allocation. Journal of Personality and Social Psychology, 110, 385-406.

Marcinkowska, U. M., Rantala, M. J., Lee, A. J., Kozlov, M. V., Toivo, A., Cai, T. H., Contreras-Garduño, J., David, O. A., Kaminski, G., Li, N. P., Onyishi, I. E., Prasai, K., Pazhoohi, F., Prokop, P., Cardozo, S. L. R., Sydney, N., Taniguchi, H., Krams, I., \& Dixson, B. J. W. (2019). Women's preferences for men's facial masculinity are strongest under favorable ecological conditions. Scientific Reports, 9, 1-10.

Marcinkowska, U. M., Jasienska, G., \& Prokop, P. (2018). A comparison of masculinity facial preference among naturally cycling, pregnant, lactating, and post-menopausal women. Archives of Sexual Behavior, 47, 1367-1374.

Meskelyte, J., \& Lyons, M. (2020). Fear of crime and preference for aggressive-formidable same-sex and opposite-sex friends. Current Psychology, 1-6.
Neuberg, S. L., Williams, K. E., Sng, O., Pick, C. M., Neel, R., Krems, J. A., \& Pirlott, A. G. (2020). Toward capturing the functional and nuanced nature of social stereotypes: An affordance management approach. Advances in Experimental Social Psychology, 62, 245-304.

Puts, D. A. (2010). Beauty and the beast: Mechanisms of sexual selection in humans. Evolution and Human Behavior, 31, 157-175.

Roccato, M., Vieno, A., \& Russo, S. (2014). The country's crime rate moderates the relation between authoritarian predispositions and the manifestations of authoritarianism: A multilevel, multinational study. European Journal of Personality, 28, 14-24.

Sacco, D. F., Holifield, K., Drea, K., Brown, M., \& Macchione, A. (2020). Dad and mom bods? Inferences of parenting ability from bodily cues. Evolutionary Psychological Science, 6, 207-214.

Sacco, D. F., Lustgraaf, C. N. J., Brown, M., \& Young, S. G. (2015). Activation of self-protection threat increases women's preferences for dominance in male faces. Human Ethology Bulletin, 30, 24-32.

Schaller, M. (2020). Evolutionary psychology meets socio-ecological psychology: The motivational psychologies of disease-avoidance and parental care. Current Opinion in Psychology, 32, 6-11.

Sell, A., Cosmides, L., Tooby, J., Sznycer, D., von Rueden, C., \& Gurven, M. (2008). Human adaptations for the visual assessment of strength and fighting ability from the body and face. Proceedings of the Royal Society b: Biological Sciences, 276, 575-584.

Sell, A., Hone, L. S., \& Pound, N. (2012). The importance of physical strength to human males. Human Nature, 23, 30-44.

Sell, A., Lukazsweski, A. W., \& Townsley, M. (2017). Cues of upper body strength account for most of the variance in men's bodily attractiveness. Proceedings of the Royal Society B: Biological Sciences, 284, 20171819.

Sherman, G. D., Haidt, J., \& Coan, J. A. (2009). Viewing cute images increases behavioral carefulness. Emotion, 9, 282-286.

Shoup, M. L., \& Gallup, G. G. (2008). Men's faces convey information about their bodies and their behavior: What you see is what you get. Evolutionary Psychology, 6, 469-479.

Smith, M. J. L., Deady, D. K., Moore, F. R., Jones, B. C., Cornwell, R. E., Stirrat, M., \& Perrett, D. I. (2012). Maternal tendencies in women are associated with estrogen levels and facial femininity. Hormones and Behavior, 61, 12-16.

Snyder, J. K., Fessler, D. M., Tiokhin, L., Frederick, D. A., Lee, S. W., \& Navarrete, C. D. (2011). Trade-offs in a dangerous world: Women's fear of crime predicts preferences for aggressive and formidable mates. Evolution and Human Behavior, 32, 127-137.

Thomas, A. G., Jonason, P. K., Blackburn, J. D., Kennair, L. E. O., Lowe, R., Malouff, J., \& Li, N. P. (2020). Mate preference priorities in the East and West: A cross-cultural test of the mate preference priority model. Journal of Personality, 88, 606-620.

Urbatsch, R. (2021). Physical formidability and acceptance of police violence. Evolution and Human Behavior, 42, 431-440.

von Rueden, C., Gurven, M., Kaplan, H., \& Stieglitz, J. (2014). Leadership in an egalitarian society. Human Nature, 25, 538-566.

Woo, B. M., \& Schaller, M. (2020). "Parental" responses to human infants (and puppy dogs): Evidence that the perception of eyes is especially influential, but eye contact is not. PLoS One, 15, e0232059.

Zebrowitz, L. A., \& Montepare, J. (2006). The ecological approach to person perception: Evolutionary roots and contemporary offshoots.

Publisher's Note Springer Nature remains neutral with regard to jurisdictional claims in published maps and institutional affiliations. 